\title{
Impact of phonology on the generation of handwritten responses: Evidence from picture-word interference tasks
}

\author{
Qingfang Zhang \\ State Key Laboratory of Brain and Cognitive Sciences, Chinese Academy of Sciences, Beijing, China \\ AND \\ MaRkus F. DAMian \\ University of Bristol, Bristol, England
}

\begin{abstract}
The degree to which phonological codes constrain handwriting is at present controversial. Two experiments used a picture-word interference paradigm in which participants wrote down the names of pictures while attempting to ignore visual distractor words presented at various time intervals (SOAs). Distractors could be orthographically and phonologically related, orthographically related only, or unrelated. We found an exclusive effect of phonology at an early SOA, and orthographic priming at a later SOA. In a second experiment, we showed that the effect of phonology was diminished when writers engaged in concurrent articulatory suppression. The results suggest a role of phonology in the generation of handwritten words that is to some extent dependent on situational circumstances.
\end{abstract}

Over the last few decades, much work has been carried out to investigate the processes and mechanisms underlying spoken word production. As a result, detailed computational accounts of speaking have been brought forward (e.g., Dell, Schwartz, Martin, Saffran, \& Gagnon, 1997; Levelt, Roelofs, \& Meyer, 1999). Relatively less work has been devoted to an understanding of written production. Much of the existing work has come from two streams of research. First, writing has been investigated as a special type of skilled motor behavior, and from such a perspective, the way in which graphemes are converted into overt written output (e.g., allographic selection, size control, muscular adjustments, etc.) has been explored in considerable detail (see, e.g., the framework proposed by van Galen, 1991). Second, several studies, mainly from a neuropsychological perspective, have investigated spelling tasks - that is, the conversion of auditory input into orthographic codes (see, e.g., Houghton \& Zorzi, 2003, for a computational model of spelling). Given that handwriting, much like speaking, typically serves to express meaning, it could be argued that the generation of written codes should be studied in close parallel to spoken production. ${ }^{1}$ In the experiments below, we apply an experimental paradigm popular in the speech production field, and we use it to investigate a central theoretical issue in handwriting.

A theoretical account of handwriting must account for how orthographic codes are accessed from conceptual knowledge. A central debate in this field concerns the role of phonological codes in this process. Early theoretical accounts (e.g., Geschwind, 1969; Luria, 1970) characterized handwriting as entirely dependent on the prior retrieval of phonological codes. According to such "phonological mediation" theories, in order to write a word, one would first have to retrieve its phonological format (i.e., covertly name the word), and these sound-based codes would subsequently be converted into graphemic codes. Claims of this type are consistent not only with the common introspective experience of how written codes are generated (Hotopf, 1980), but also with the observation of phonologically conditioned spelling errors (e.g., homophone substitutions such as there for their, or quasi-homophone substitutions such as dirth for dearth; Aitchison \& Todd, 1982). Some experimental evidence also supports the phonological mediation hypothesis, such as the finding that spelling errors generated by brain-impaired patients and normal writers occur more frequently on picture names with inconsistent rather than consistent spelling (Aitchison \& Todd, 1982). This finding implies online competition between two orthographic codes for inconsistent items and hence provides evidence of phonological involvement in writing. Additionally, many neuropsychological patients with writing disorders exhibit comparable impairments in spoken and written language production (Basso, Taborelli, \& Vignolo, 1978; Head, 1926; Hécaen \& Angelergues, 1965; Luria, 1966), as the phonological mediation hypothesis predicts. 
However, the phonological mediation account has largely fallen out of favor, because more recently, numerous neuropsychological studies have demonstrated dissociations between spoken and written production, such as in cases of acquired brain damage in which patients could, for instance, name a picture, but not write its name, or vice versa. Rapp, Benzing, and Caramazza (1997) presented the case of a neurologically impaired individual who was often able to write the name of a picture correctly while being unable to provide the correct spoken name of the picture. Miceli, Benvegnù, Capasso, and Caramazza (1997) reported a patient who, when presented with a picture, sometimes generated different spoken and written responses (e.g., when presented with a picture representing pliers, would say "pincers" but write saw). Additionally, spelling errors produced by agraphic patients can be phonologically illegal (e.g., Caramazza \& Miceli, 1990). Findings of this type motivated the "orthographic autonomy" hypothesis, according to which written representations can be accessed directly from semantic representations without phonological mediation (e.g., Rapp \& Caramazza, 1997).

Because of these studies, it is by now relatively uncontroversial that writing does not necessarily depend on prior successful phonological retrieval. This conclusion, however, does not necessarily imply that in unimpaired writing, phonological codes do not contribute to the selection of orthographic codes. Relatively few empirical studies have addressed the relationship between phonological and orthographic codes in experimental settings and with chronometric tasks, and the results have not been consistent. Bonin, Fayol, and Peereman (1998) employed a task in which participants produced the written names of pictures, and the pictorial stimuli were preceded by word primes that were presented for a very short duration and were forward and backward masked. A facilitatory effect of orthographic overlap was obtained when primes were presented for 34 and $51 \mathrm{msec}$, which crucially was not modulated by whether prime and picture name were homophonic ( pype-pipe) or not (pope-pipe). This suggests that the role of phonology in writing is relatively limited. On the other hand, Bonin, Peereman, and Fayol (2001) used a written picture-naming task and manipulated sound-to-print consistency of picture labels and the position of inconsistent units. The consistency between phonology and orthography was manipulated either at the lexical or at the sublexical level. The results showed no effect of phonographic consistency. However, when Bonin et al. (2001) varied the position of the inconsistent units on their initial part (initial consonant or vowel) or their middle or final part (vowel or vowel-consonant units), they found that initial inconsistency, but not middle or final inconsistency, of picture names had an effect on writing latencies. This finding suggests that phonological codes indeed influenced orthographic encoding in writing. Furthermore, Bonin et al. (2001) used a spelling-todictation task to explore why consistency affected written picture-naming latencies only in the case of initial consistent units. The results showed that middle or final inconsistencies affected written latencies in a spelling-to- dictation task, and the data were interpreted in terms of a differential semantic influence in written picture naming versus spelling-to-dictation. Overall, Bonin et al.'s (2001) study provided evidence for the role of phonological codes in unimpaired written production.

As summarized above, the influence of phonological codes in writing remains controversial. To investigate this issue further, the two experiments reported below used a written picture-naming task with a picture-word interference (PWI) manipulation. The PWI task is widely used to study the processes involved in speech production. Participants are asked to name target pictures while ignoring written or spoken distractor words. Results have consistently shown that it is impossible to avoid distractor processing, because specific types of relationships between picture names and distractor words systematically affect the time that it takes to name the picture. Typically, a semantic relationship between a target picture and a distractor ( $\mathrm{dog}_{-}$ wolf) slows response time relative to an unrelated condition, whereas form overlap ( $d o g-d o l l)$ speeds responses (e.g., Glaser \& Düngelhoff, 1984; Lupker \& Katz, 1981; Schriefers, Meyer, \& Levelt, 1990; Starreveld \& La Heij, 1995). These two phenomena-semantic interference and phonological facilitation - have been taken to provide important constraints on models of spoken word production (e.g., Levelt et al., 1999). A further variable that is commonly manipulated in PWI tasks is the stimulus onset asynchrony (SOA) interval between picture and distractor. Commonly, distractor onsets prior to target onsets are denoted as "negative SOA," and distractor onsets lagging picture onset are called "positive SOA." Manipulating the "entry time" of the distractor information, relative to the onset of the picture, allows one to tap into successive stages of target processing as a response is being prepared. Previous studies have reported semantic and phonological effects in association with specific SOAs, which has been taken as evidence regarding the characteristics of lexical access in spoken production (see, e.g., Damian \& Martin, 1999; Schriefers et al., 1990; Starreveld, 2000; Starreveld \& La Heij, 1995).

Very few studies have applied the PWI methodology to written picture naming, but the existing results show clear parallels with findings for spoken picture naming. Bonin and Fayol (2000) directly compared spoken and written picture naming while instructing participants to ignore semantically or phonologically related distractor words presented at various SOAs. They found relatively similar findings with spoken and written responses, with semantic interference and phonological facilitation effects in both response domains, and a similar pattern regarding the time course as indicated by the SOA patterns. More recently, Damian and Stadthagen-Gonzalez (2009, Experiment 2) showed that when participants wrote down adjective-noun phrases in response to colored objects (blue duck), visually presented distractors form-related to the noun (dust) facilitated responses. The same pattern has been found with spoken responses (e.g., Damian \& Dumay, 2007) and could be interpreted as planning of the entire utterance prior to response onset. Overall, the existing studies suggest that with written as with spoken re- 
sponses, form relatedness between distractor and picture name entails reliable facilitation.

The two experiments below were aimed at identifying the relative contributions of phonological and orthographic variables to this facilitation effect. We used a PWI task with written responses and visually presented distractors, and we compared facilitation arising from distractors that were orthographically and phonologically related to the picture name (hand-sand) with facilitation from distractors that were orthographically equally similar, but phonologically less related (hand-wand). Given that the earlier studies using PWI and written picture naming had confounded orthographic and phonological relatedness, they did not permit identification of the locus of form-related facilitation. However, it is quite plausible to hypothesize that with visually presented distractors, purely orthographic facilitation is present in this task: Printed distractors should access the orthographic lexicon, and given that written picture naming involves the retrieval of orthographic codes, form overlap at this level should have a facilitatory influence. The central question is whether the presence or absence of a phonological relationship between picture name and distractor shows discernible effects above and beyond graphemic priming. If so, the conclusion would be that written picture naming involves the coactivation of phonological codes. We varied picture-distractor onset intervals from 0 to $+200 \mathrm{msec}$, a range that in studies on spoken production typically renders form facilitation effects (e.g., Damian \& Martin, 1999; Schriefers et al., 1990; Starreveld \& La Heij, 1995).

In investigating this issue, the two experiments implemented what we now consider standard practice in studies using the PWI task in the spoken domain - namely, forming unrelated picture-word pairings by recombining related pictures and words so that they were no longer related. This is preferable to a design in which different distractor words are used in different conditions (e.g., Schriefers et al., 1990), because properties of the distractors themselves (such as frequency; see, e.g., Miozzo \& Caramazza, 2003) may affect picture naming times differentially. By reusing the distractors from the related condition in the unrelated condition, a potential source of variance was eliminated. As outlined above, in the present study, we used two different related conditions (orthographically and phonologically related vs. orthographically related), and constraints on stimulus selection prevented use of the same distractor words in both conditions. Hence, for each target picture, two distractor words were chosen, one that was orthographically and phonologically related (i.e., a rhyme: hand-sand) and one that was orthographically related but phonologically dissimilar (hand-wand). For each condition, a separate unrelated baseline condition was then formed by recombining pictures and words within each group so as to avoid form relatedness. By doing so, we ensured that when we assessed the impact of relatedness, the same targets and distractors occurred within each type of relatedness, only in different combinations. Concerning our assessment of the impact of phonological relatedness, we then compared relative priming arising from each of the two types of relatedness; however, we did not consider it insightful to compare the two related conditions directly, because (as outlined above) differences in lexical or other properties between the two sets of distractors might also affect latencies.

It should also be noted that because of the inevitable confound between sound and spelling in English, our orthographically related but phonologically unrelated condition (hand-wand) included some degree of phonological overlap (in this example, the final phonemes $/ \mathrm{n} /$ and $/ \mathrm{d} /$ ). This confound rendered this condition more similar to the orthographically and phonologically related condition (hand-sand) than it ideally should, and it made it more difficult to document a potential role of phonology in written production. However, as the results of the first experiment will show, the two conditions indeed deviated in characteristic ways concerning their respective degrees of facilitation.

\section{EXPERIMENT 1}

\section{Method}

Participants. Thirty students at the University of Bristol participated in the experiment. They were paid a small fee or given course credit for participation. Participants were native English speakers and all had normal or corrected-to-normal vision.

Materials. Twenty-three line drawings of common objects served as the targets. All had monosyllabic names, with a Kučera-Francis (1967) frequency of 88 and an average frequency of 96 per million in the CELEX database of written English (Baayen, Piepenbrock, $\&$ Gulikers, 1995). Each picture was paired with two types of formrelated monosyllabic distractor words: (1) Orthographically related, but phonologically dissimilar, distractor words $(\mathrm{O})$ shared spelling with the picture name, but the central vowel was different (handwand); (2) orthographically and phonologically related distractor words (OP) shared spelling and phonology with the picture names (hand-sand). Distractors in each condition were then recombined with the picture names to form two corresponding unrelated (U) conditions in which there was only minimal phonological or orthographic overlap. Semantic or associative relationships between picture name and distractor were avoided in all combinations.

The lexical properties of the distractor words are shown in Table 1. Items were statistically matched across the $\mathrm{O}$ and $\mathrm{OP}$ conditions on word length in letters and phonemes, log Kučera-Francis frequency, $\log$ CELEX written and spoken frequency, and bigram frequency. For both $\mathrm{O}$ and $\mathrm{OP}$ pairings, we estimated the degree of orthographic and phonological overlap between distractor words and corresponding picture names with a similarity measure ranging from 0 to 1 , computed as the average of (1) the fraction of shared letters/phonemes between distractor and picture label in and out of position and (2) the fraction of shared letters/phonemes that occurred in the same position within each word (this index, also used in Damian \& Martin, 1999, was adapted from Lesch \& Pollatsek, 1993). The values shown in Table 1 indicate that distractors in the $\mathrm{O}$ and the OP conditions were matched concerning their orthographic similarity to the picture name. Numbers in parentheses indicate overlap between the corresponding unrelated picture-distractor combinations, showing only minimal form overlap. The $\mathrm{O}$ distractors should ideally be as phonologically dissimilar with respect to the picture names as the $U$ distractors. However, this is in practice impossible to accomplish due to the substantial confounding between orthography and phonology in English. Note that, as outlined above, this confound works against documenting a potential impact of phonology in this task. ${ }^{2}$

Design. The experimental design included relatedness (related vs. unrelated), type of relatedness (orthographically and phonologically related vs. orthographically related), and SOA $(0,+100$, and 
Table 1

Mean Lexical Properties of Distractor Stimuli Used in Experiments 1 and 2

\begin{tabular}{lcc}
\hline & $\begin{array}{c}\text { Orthographically } \\
\text { Related }\end{array}$ & $\begin{array}{c}\text { Orthographically and } \\
\text { Phonologically Related }\end{array}$ \\
\hline Word length: letters & 4.2 & 4.4 \\
Word length: phonemes & 3.3 & 3.5 \\
Kučera-Francis frequency $(\log )$ & 3.3 & 3.2 \\
CELEX: written frequency $(\log )$ & 3.3 & 3.2 \\
CELEX: spoken frequency $(\log )$ & 2.9 & 2.2 \\
Bigram frequency: token $(\log )^{*}$ & 3.0 & 3.0 \\
Overlap with target: phonemes $^{\dagger}$ & $0.27(0.02)$ & $0.58(0.05)$ \\
Overlap with target: letters $^{\dagger}$ & $0.52(0.04)$ & $0.56(0.05)$ \\
\hline
\end{tabular}

*Bigram frequencies taken from N-Watch (Davis, 2005) and based on COBUILD corpus. †Numbers in parentheses indicate overlap in the corresponding unrelated condition.

$+200 \mathrm{msec}$ ) as within-participants and within-items factors. For each participant, each picture was displayed under every relatedness and SOA condition, resulting in 276 combinations. Trials were blocked by SOA. The order in which participants received the SOA blocks was varied according to a Latin square design. Items were presented in a pseudorandom fashion such that any particular picture was never repeated on consecutive trials, and pictures with the same onset were not presented consecutively. A new random sequence was generated for each participant and each block.

Apparatus. Stimuli were presented via an IBM-compatible computer on a 17-in. monitor using DMDX 3.0 (Forster \& Forster, 2003). Distractor words were presented in black 18-point Arial bold font, centrally superimposed on the target pictures. Picture distractor displays were displayed toward the bottom of the screen, rather than in the more customary central position, in order to minimize eye movements between the displays and the writing surface. Written responses were collected with a WACOM Intuos A4 graphic tablet and a WACOM inking digitizer pen. A sheet of paper was divided into four columns, each column consisting of 23 lines, so that a sheet of paper recorded 92 picture names, which corresponds to one SOA block. The graphics tablet recorded the time of initial contact of the stylus with the tablet, relative to target picture onset, within each response period.

Procedure. Participants were tested individually. At the beginning of the experiment, they were presented with the target pictures, together with the targets' names, on the computer screen. They were asked to study the correct names and to use them in the experiment. After having familiarized themselves with the picture names, two practice blocks followed. Participants were instructed to hover the stylus just above the corresponding line on the response sheet in anticipation of the response, so that the response would not require an arm movement. Additionally, participants who dropped the stylus onto the sheet at the beginning of the trial, then paused until they had identified the response, and subsequently started moving the pen, were explicitly instructed not to do so during the practice block. It was ensured that all participants complied with these instructions in the experimental part.

In the first practice block, each target picture was presented in random order, and participants were asked to write down the picture names on the response sheet; responses other than the ones expected were corrected. In the second practice block, the pictures were accompanied by unrelated distractor words, and participants were instructed to write down picture names while attempting to ignore distractor words. Subsequently, three experimental blocks of 92 trials each, corresponding to the three SOAs, were carried out, and the participants' task was the same as in the second practice block. Breaks were provided after half of each block was finished and between the three blocks. Each testing session consisted of 276 trials, and the whole experiment took approximately $30 \mathrm{~min}$ to complete for each participant.
On each experimental trial, participants first viewed a fixation dot positioned toward the bottom of the screen for $500 \mathrm{msec}$. After a black period of $500 \mathrm{msec}$, the target picture was presented for 4,000 msec. Distractor words were presented at the appropriate time interval relative to object onset and remained on the screen with the target object. An intertrial interval of $1,000 \mathrm{msec}$ was used. Response times were recorded from the onset of the target picture to the response.

\section{Results}

Response sheets were inspected for written errors, and incorrect responses were excluded from the response time analysis $(1.1 \%)$. Latencies faster than $300 \mathrm{msec}$ or slower than $1,800 \mathrm{msec}$ were considered outliers and discarded $(0.6 \%)$. Table 2 presents the mean latencies and error percentages, varied by relatedness, type of relatedness, and SOA.

The results were analyzed using a linear mixed effects methodology (Baayen, Davidson, \& Bates, 2008; Bates, 2005). An ANOVA was conducted on the response latencies, with relatedness, type of relatedness, and SOA included as the variables. We found a main effect of relatedness $\left[F(1,8128)=69.58, M S_{\mathrm{e}}=1,371,661, p<.001\right]$, with related responses $26 \mathrm{msec}$ faster than unrelated ones. The main effect of type of relatedness was marginally significant $\left[F(1,8128)=3.63, M S_{\mathrm{e}}=71,721, p=.057\right]$, with responses $6 \mathrm{msec}$ faster in the $\mathrm{O}$ condition than in the OP condition. The main effect of SOA was also significant $\left[F(2,8128)=73.64, M S_{\mathrm{e}}=1,453,796, p<.001\right]$.

Table 2

Experiment 1: Mean Response Latencies (RTs, in Milliseconds) and Mean Error Percentages (PEs)

\begin{tabular}{|c|c|c|c|c|c|c|c|c|}
\hline \multirow[b]{3}{*}{ Condition } & \multicolumn{6}{|c|}{ SOA (msec) } & & \\
\hline & \multicolumn{2}{|c|}{0} & \multicolumn{2}{|c|}{+100} & \multicolumn{2}{|c|}{+200} & \multicolumn{2}{|c|}{ Overall } \\
\hline & RT & $\mathrm{PE}$ & RT & $\mathrm{PE}$ & RT & $\mathrm{PE}$ & RT & $\mathrm{PE}$ \\
\hline $\mathrm{O}$ & 681 & 1.2 & 663 & 0.9 & 648 & 1.0 & 663 & 1.0 \\
\hline $\mathrm{U}$ & 692 & 1.6 & 718 & 1.4 & 651 & 1.0 & 687 & 1.3 \\
\hline Effect & +11 & +0.4 & +55 & +0.5 & +3 & 0.0 & +24 & +0.3 \\
\hline OP & 674 & 1.3 & 676 & 1.2 & & 0.6 & 667 & 1.0 \\
\hline $\mathrm{U}$ & 710 & 1.3 & 719 & 1.3 & 658 & 0.9 & 695 & 1.1 \\
\hline Effect & +36 & 0.0 & +43 & +0.1 & +7 & +0.3 & +28 & +0.1 \\
\hline
\end{tabular}

Note-SOA, stimulus onset asynchrony; $\mathrm{O}$, orthographically related; OP, orthographically and phonologically related; U, unrelated. 
Additionally, we found an interaction between relatedness and SOA $\left[F(2,8128)=16.54, M S_{\mathrm{e}}=326,504, p<.001\right]$, with relatedness effects of 24,49 , and $5 \mathrm{msec}$ for SOAs $=$ $0,+100$, and $+200 \mathrm{msec}$, respectively. The interactions between relatedness and type of relatedness, and between type of relatedness and SOA, were not significant (both $F \mathrm{~s}<1)$. We obtained a significant three-way interaction of relatedness, type of relatedness, and SOA $[F(2,8128)=$ $\left.3.03, M S_{\mathrm{e}}=59,811, p=.048\right]$.

To follow up on the latter finding, we analyzed simple effects of the variables relatedness and type of relatedness, conducted separately for each level of SOA. At SOA = $0 \mathrm{msec}$, we found a significant main effect of relatedness $\left(24-m s e c\right.$ facilitation) $\left[F(1,2692)=21.33, M S_{\mathrm{e}}=\right.$ $379,913, p<.001]$, no effect of type of relatedness $(F=$ $1.60, p=.206)$, and, importantly, an interaction between relatedness and type of relatedness $[F(1,2692)=5.63$, $\left.M S_{\mathrm{e}}=100,280, p=.018\right]$, reflecting the fact that facilitation in the $\mathrm{O}$ condition $(11 \mathrm{msec})$ was smaller than in the OP condition $(36 \mathrm{msec})$. The facilitatory effect in the $\mathrm{O}$ condition was not significant $(F=2.52, p=.112)$, but it was in the OP condition $\left[F(1,1343)=24.72, M S_{\mathrm{e}}=\right.$ $434,540, p<.001]$. At SOA $=+100 \mathrm{msec}$, we found a significant main effect of relatedness (49-msec facilitation) $\left[F(1,2715)=85.44, M S_{\mathrm{e}}=1,628,698, p<.001\right]$, no effect of type of relatedness $(F=1.77, p=.183)$, and no interaction between relatedness and type of relatedness $(F=1.40, p=.236)$. At SOA $=+200 \mathrm{msec}$, neither the main effects nor the interaction was significant (all $\left.F_{\mathrm{S}}<1\right)^{3}$

A parallel analysis was conducted on the error percentages. None of the main effects or interactions reached significance $\left(F_{\mathrm{S}} \leq 1.51, p \mathrm{~s} \geq .201\right)$.

\section{Discussion}

The results of Experiment 1 showed reliable facilitation from form-related distractors under SOAs of 0 and $+100 \mathrm{msec}$, but at SOA $=+200 \mathrm{msec}$, the effects were very small and not significant. This pattern is generally compatible with previous studies on spoken production; for example, Damian and Martin (1999, Experiment 1) found phonological facilitation from visually presented distractors ranging from -200 to $+100 \mathrm{msec}$, but no significant effect at $+200 \mathrm{msec}$. The implication is that with substantially large positive SOAs, the distractor may be presented too late, relative to picture processing, to affect form encoding. The general magnitude of the facilitation effects in Experiment 1 is also comparable with previous studies on written (e.g., Bonin \& Fayol, 2000) and spoken production.

More importantly, we found a significant interaction between relatedness and type of relatedness at SOA = $0 \mathrm{msec}$, under which the difference between the $\mathrm{O}$ effect $(11 \mathrm{msec})$ and the OP effect $(36 \mathrm{msec})$ was statistically significant. This finding implies that form-related facilitation at this SOA was modulated by phonological factors, because the size of priming was determined mainly by the presence or absence of a phonological relationship between target and distractor. By contrast, under the SOA of $+100 \mathrm{msec}$, facilitation was no longer exclusively dominated by phonological processing and showed a clear graphemic component, evidenced by the fact that both the $\mathrm{OP}$ and the $\mathrm{O}$ condition rendered comparable degrees of facilitation. Finally, at SOA $=+200 \mathrm{msec}$, neither condition induced significant priming, implying that the distractor was presented too late to have an impact on retrieval of the target name. The underlying premise of varying SOAs in PWI tasks is that it allows the distractor to tap into successive stages of target processing, with "early" (i.e., more negative) SOAs tapping early stages of target processing, and "late" (more positive) SOAs affecting later stages of target retrieval. Under these assumptions, our results indicate that an early stage of written target name retrieval is constrained by phonological variables (i.e., facilitation at this stage is mainly determined by phonological target-distractor relatedness), but this stage is followed by a subsequent processing stage in which graphemic overlap by itself is sufficient to render substantial facilitation. We will discuss the specific consequences of the results concerning the time course of handwriting in the General Discussion in more detail.

It should be noted that at $\mathrm{SOA}=0 \mathrm{msec}$, the latency means for the O-unrelated and OP-unrelated conditions diverge, with the O-unrelated mean being substantially shorter than the OP-unrelated mean. This could be interpreted as implying that the reduced priming effect in the $\mathrm{O}$, in comparison with the OP, condition under this SOA was at least partially caused by a faster baseline mean, rather than less priming in the related condition. However, different distractor words were used in the OP and $\mathrm{O}$ conditions, with linguistic and other properties that were only partially matched and that by themselves, independent of the relatedness manipulation, could have affected picture-naming latencies. By contrast, within either the $\mathrm{OP}$ or the $\mathrm{O}$ condition, the same distractor words were used for the related and the unrelated conditions; hence, we believe that the only valid comparison concerns the degree of priming within each type of relatedness. Here, the presence of an interaction between relatedness and type of relatedness suggests a role of phonology in handwriting. Overall, therefore, the results indicate that certain stages of handwritten production are clearly constrained by phonological variables, a conclusion that agrees with previous findings such as those reported by Bonin et al. (2001).

\section{EXPERIMENT 2}

In the second experiment, we investigated the possibility that reliance on phonological codes in handwriting is to a certain extent "optional"- - that is, that handwriting is possible without explicit input from the phonological system (as the orthographic autonomy hypothesis suggests) and that the influence of phonological codes can be diminished by means of certain experimental manipulations. To this aim, we employed an articulatory suppression task that was carried out concurrently with the primary picture name writing task. When participants engage in repeated articulation of a prespecified string, performance on primary short-term memory tasks is adversely affected (e.g., Baddeley, Lewis, \& Vallar, 1984). It is generally assumed 
that participants perform such short-term memory tasks by generating a phonological representation and keeping it in memory by means of subvocal rehearsal, and that articulatory suppression interferes with the maintenance of the buffered phonological representation. For our purpose of investigating the influence of phonological codes in the generation of handwritten responses, it was possible that a concurrent articulatory suppression task might diminish such a role by "saturating" the phonological system.

Combining a written task with articulatory suppression is not novel: Smyth and Silvers (1987) investigated the role of sensory feedback in sentence writing by manipulating the sight of the hand, as well as the absence or presence of articulatory suppression, which consisted of either repeating a nonsense syllable aloud or counting. Kandel, Álvarez, and Vallée (2006) investigated the potential role of syllabic representations in handwriting by asking participants to write down visually presented words. In order to suppress phonological recoding of the stimulus words, which may by itself render syllabic effects, the authors asked their participants to engage in concurrent articulatory suppression while performing the primary task: At the beginning of each trial, they counted aloud starting at 1 , and they continued until the trial was finished. Despite this manipulation, Kandel et al. obtained evidence for syllabic effects in handwriting, such that a particular letter sequence was produced faster when it occurred within a syllable, as opposed to when the same letter sequence straddled a syllable boundary. Studies such as these suggest that participants are principally able to write words while concurrently carrying out an articulatory suppression task. The issue in which we were interested was whether such a secondary task would diminish the influence of phonological variables in the PWI task that had emerged in our first experiment. If so, then the conclusion would have to be that the role of phonology in handwriting may not be particularly critical, but is perhaps a secondary consequence of the fact that access to phonological codes of picture names is relatively fast, effortless, and automatic and hence affects the relatively slower and perhaps more strategic retrieval of graphemic codes. Hence, suppression of the generation of phonological codes in written picture naming might diminish this source of input to the graphemic level and force the system to rely predominantly on the "autonomous" link from conceptual to graphemic knowledge.

The second experiment was identical in all aspects to the first, except that participants engaged in articulatory suppression while generating their written responses. To our knowledge, no prior studies exist in which participants attempted to perform written picture naming while engaging in articulatory suppression (in Smyth and Silvers's, 1987, study, participants wrote memorized sentences, and in Kandel et al., 2006, participants copied printed words), so from the outset we considered the possibility that the effects of the secondary task might be overall quite detrimental to performance. However, as is shown below, this turned out not to be the case, with overall response latencies that were somewhat, but not dramatically, slower than those found in the first experiment. Furthermore, it is worth noting that the impact of articulatory suppression on the retrieval of spoken codes was investigated previously by Wheeldon and Levelt (1995). In order to investigate the dynamics of phonological encoding, those authors presented Dutch-English bilinguals with English words and asked them to generate the Dutch translation silently and then to monitor for a particular phoneme within the generated code. In their first experiment, Wheeldon and Levelt demonstrated that participants were still able to carry out this task while engaging in concurrent articulatory suppression, and they concluded that the processing system occupied by articulatory suppression does not play a critical role in the phonological encoding of spoken responses. This inference might compromise our intention, in our second experiment, to diminish the influence of phonological codes on graphemic production with such a concurrent task. However, it could be argued that participants in Wheeldon and Levelt's study engaged in a metalinguistic decision task on internally generated phonological codes, and that for this reason the processing dynamics may be different from "proper" spoken utterances. And as will be shown below, the results of our second experiment clearly demonstrate that articulatory suppression indeed had observable consequences on written picture naming.

\section{Method}

Participants. Thirty students at the University of Bristol, none of whom had taken part in the first experiment, participated in the experiment. They received a small payment fee for participation. All were native English speakers and had normal or corrected-tonormal vision.

Materials, Design, Apparatus, and Procedure. These were identical to those of Experiment 1, except for the addition of the articulatory suppression procedure. Participants were instructed that their main task was to write down the names of presented pictures as quickly and accurately as possible while attempting to ignore distractor words superimposed on the pictures. At the same time, they were asked to count aloud from 1 to 10 , starting on each trial as soon as the fixation dot appeared on the screen. Informal tests conducted prior to setting up the experiment had shown that the time involved in counting to 10 roughly covered the time that it took participants to prepare and write down the picture name. We included the same two practice blocks as in Experiment 1. After the practice blocks, all participants reported that they were able to carry out the picturenaming task while counting simultaneously.

\section{Results}

Incorrect responses were excluded from the response time analysis $(1.8 \%)$. Latencies faster than $300 \mathrm{msec}$ or slower than $1,800 \mathrm{msec}$ were considered outliers and discarded (1.1\%). The overall average response latency in this experiment was $729 \mathrm{msec}$, as opposed to 675 in the first experiment. The 54-msec difference was significant $\left[F(1,16146)=549.99, M S_{\mathrm{e}}=11,781,552, p<\right.$ $.001]$; hence, the addition of the articulatory suppression procedure slowed written word production significantly, although in a relatively subtle manner. Participants also made more errors in the second experiment $(1.8 \%)$ than in the first experiment $(1.1 \%)\left[F(1,16558)=12.55, M S_{\mathrm{e}}=\right.$ $1,761, p<.001]$. 
Table 3

Experiment 2: Mean Response Latencies (RTs, in Milliseconds) and Mean Error Percentages (PEs)

\begin{tabular}{|c|c|c|c|c|c|c|c|c|}
\hline \multirow[b]{3}{*}{ Condition } & \multicolumn{6}{|c|}{ SOA } & & \\
\hline & \multicolumn{2}{|c|}{0} & \multicolumn{2}{|c|}{+100} & \multicolumn{2}{|c|}{+200} & \multicolumn{2}{|c|}{ Overall } \\
\hline & RT & $\mathrm{PE}$ & RT & PE & RT & PE & RT & $\mathrm{PE}$ \\
\hline $\mathrm{O}$ & 735 & 2.3 & 730 & 1.9 & 712 & 0.9 & 726 & 1.7 \\
\hline U & 747 & 2.2 & 771 & 1.7 & 720 & 1.9 & 746 & 1.9 \\
\hline Effect & +12 & -0.1 & +41 & -0.2 & +8 & +1.0 & +20 & +0.2 \\
\hline OP & 732 & 2.0 & 738 & 2.0 & 702 & 1.0 & 724 & 1.7 \\
\hline $\mathrm{U}$ & 748 & 0.9 & 767 & 1.9 & 720 & 2.6 & 745 & 1.8 \\
\hline Effect & +16 & -1.1 & +29 & -0.1 & +18 & +1.6 & +21 & +0.1 \\
\hline
\end{tabular}

Note-SOA, stimulus onset asynchrony; O, orthographically related; $\mathrm{OP}$, orthographically and phonologically related; $\mathrm{U}$, unrelated.

Table 3 presents the mean latencies and error percentages, varied by relatedness, type of relatedness, and SOA.

An ANOVA was conducted on the response latencies, with relatedness, type of relatedness, and SOA as the variables. We found a main effect of relatedness $[F(1,8030)=$ $\left.40.57, M S_{\mathrm{e}}=825,108, p<.001\right]$, with related responses $20 \mathrm{msec}$ faster than unrelated ones. The main effect of type of relatedness was not significant $(F<1)$. The main effect of SOA was significant $\left[F(2,8030)=46.34, M S_{\mathrm{e}}=942,517\right.$, $p<.001]$. Additionally, we found an interaction between relatedness and SOA $\left[F(2,8030)=4.09, M S_{\mathrm{e}}=83,117\right.$, $p=.017]$, with relatedness effects of 14,34 , and $13 \mathrm{msec}$ for $\operatorname{SOAs}=0,+100$, and $+200 \mathrm{msec}$, respectively. All other interactions were not significant $\left(F_{\mathrm{S}}<1\right)$.

To render the analysis comparable to that for the first experiment, we analyzed simple effects of the variables relatedness and type of relatedness, separately for each level of SOA, despite the nonsignificant three-way interaction of relatedness, type of relatedness, and SOA. At SOA = $0 \mathrm{msec}$, we found a significant main effect of relatedness $\left[F(1,2669)=6.65, M S_{\mathrm{e}}=131,160, p=.010\right]$, no effect of type of relatedness $(F<1)$, and no interaction between the two $(F<1)$. At SOA $=+100 \mathrm{msec}$, we found a significant main effect of relatedness $[F(1,2672)=37.79$, $\left.M S_{\mathrm{e}}=739,848, p<.001\right]$, no effect of type of relatedness $(F<1)$, and no interaction between relatedness and type of relatedness $(F<1)$. At SOA $=+200 \mathrm{msec}$, we found a significant main effect of relatedness $[F(1,2689)=6.63$, $\left.M S_{\mathrm{e}}=115,625, p=.010\right]$, no effect of type of relatedness $(F<1)$, and no interaction between relatedness and type of relatedness $(F=1.11, p=.292)$.

A parallel analysis was conducted on the error percentages. None of the main effects were significant (all $F$ s $<1)$. Only the interaction between relatedness and SOA was significant $\left[F(2,8268)=4.17, M S_{\mathrm{e}}=711\right.$, $p=.016]$, with relatedness effects of $-0.7 \%,-0.2 \%$, and $+1.3 \%$ for the SOAs of $0,+100$, and $+200 \mathrm{msec}$, respectively. All other interactions were not significant (all $F_{\mathrm{s}} \leq 1.68, p \mathrm{~s} \geq .201$ ).

\section{Discussion}

In comparison with the results of the first experiment, those from the second experiment can be characterized as follows: Overall latencies were moderately slowed, and error rates raised, by the addition of the articulatory suppression procedure. As in the first experiment, the maximum extent of form-related facilitation was obtained at $\mathrm{SOA}=+100 \mathrm{msec}$, with relatively less facilitation at $\mathrm{SOA}=0 \mathrm{msec}$, and even less at $\mathrm{SOA}=+200 \mathrm{msec}$. In the first experiment, form-related facilitation was modulated by phonological relatedness at the earliest SOA $(0 \mathrm{msec})$. No such effect was obtained in the second experiment; in other words, the priming found here was predominantly based on graphemic properties. Overall, the results suggest that the role of phonology in the generation of handwritten responses is to some extent "optional," in that it can be influenced by experimental manipulations such as the addition of an articulatory suppression manipulation.

It is important to note that it is unlikely that the second experiment might somehow have "missed" a genuine effect of phonology by using an inappropriate range of SOAs. Given the overall slowed latencies compared with those in the first experiment, effects emerging at particular SOAs in that experiment could potentially have shifted toward a more positive SOA. Since the critical effect in Experiment 1 was found at $\mathrm{SOA}=0 \mathrm{msec}$, it might have emerged at $\mathrm{SOA}=+100 \mathrm{msec}$ in Experiment 2; however, the results clearly show that this was not the case.

Our choice of the articulatory suppression technique was motivated by the fact that previous research (Baddeley \& Hitch, 1974) had clearly identified its consequences concerning the phonological loop in working memory. Furthermore, studies had demonstrated that the task can be used in conjunction with the generation of written responses (Kandel et al., 2006; Smyth \& Silvers, 1987). The possibility must be noted, however, that the reduced influence of phonological relatedness in the second, compared with the first, experiment may have been caused by the dual-task situation itself, rather than by the fact that the secondary task involved phonological processing. Future studies may therefore choose to implement a secondary task that has no phonological component (e.g., finger tapping with the non-response hand); we predict that despite a general slowing due to the dual-task situation, the pattern of results will show clear evidence of a role of phonology and hence resemble the one observed in our first experiment.

\section{GENERAL DISCUSSION}

In two experiments, we investigated the degree to which phonological codes support the written production of single words. In an adaptation of the PWI task, participants wrote down the names of objects while trying to ignore visually presented distractor words superimposed on the target, and the time interval between word and distractor onset (SOA) was varied. The first experiment showed that words that were form related to the target name facilitated responses; specifically, at the earliest SOA $(0 \mathrm{msec})$, words that were orthographically, but also phonologically, related (hand-sand) showed priming, whereas those that were only orthographically related (hand-wand) did not. The significant interaction between relatedness and type 
of relatedness obtained under this SOA suggests a role of phonological codes in handwriting. At SOA $=+100 \mathrm{msec}$, both types of distractors showed comparable facilitation, suggesting that here, priming was constrained by graphemic variables. At $\mathrm{SOA}=+200 \mathrm{msec}$, no facilitation was found, suggesting that the distractor was presented too late to influence form encoding. In the second experiment, we added an articulatory suppression manipulation: Participants counted aloud while writing down the picture names. In this experiment, we observed a moderate slowing of response latencies relative to latencies in the first experiment, and crucially, the effect of phonology shown in the first experiment disappeared. We interpret these findings as showing that articulatory suppression diminished the phonological contribution to handwriting.

The finding that the articulatory suppression procedure modulated the effect of form relatedness in our PWI task is not trivial, given previous studies. As summarized above, Wheeldon and Levelt's (1995) experiments on the monitoring of internally generated spoken utterances had indicated that articulatory suppression affects a phonetic/ articulatory level of spoken production but leaves the production of an abstract phonological code relatively unaffected. On the basis of this argument, one could have predicted that the transmission of activation to the orthographic lexicon via the phonological pathway would remain undiminished. The exact way in which articulatory suppression interacts with the retrieval of codes in written and spoken production remains to be clarified (see below); however, our results indicate that the influence of phonological codes onto handwritten production is not mandatory and universal, because it can be modulated via experimental manipulations.

It is worth noting that with the picture-word method chosen here, potential effects of phonology in handwriting can only be demonstrated indirectly - that is, via an interaction between target and distractor processing. As outlined in the introduction, our choice of using visually presented distractors worked against the objective of documenting such phonological effects because both target response generation and distractor processing involve primarily orthographically based representations. It is quite likely (although at present untested) that with the use of spoken, rather than visual, distractors, the effects of phonology suggested in our first experiment would emerge much more forcefully because distractor processing would now be primarily phonologically based.

In both experiments, each target picture was presented and named numerous times by each participant. Such a design is very common in studies using the PWI paradigm, mainly because severe constraints on the availability of pictorial stimuli make it difficult and often impossible to design experiments that avoid repetition. Because stimulus repetition does not eliminate the "classical" effects of semantic interference and form-related facilitation, it is not typically perceived as problematic. However, it could be argued that the results of the present study underestimate genuine effects of phonology in handwriting because repeated target processing may diminish the influence of phonology. We acknowledge this possibility; however, for practical reasons we see great difficulties in designing alternative experiments that would avoid such stimulus repetition. Additionally, despite the fact that stimulus repetition may conceivably counteract our aim of documenting phonological effects, we take the main finding of the first experiment to consist of the presence of a phonological effect.

What are the consequences of these findings for processing models of handwriting? To reiterate, the logic of SOA variations in PWI tasks is that it allows the distractor to tap into successive stages of target processing, with "early" (i.e., more negative) SOAs tapping "early" stages of target processing, and "late" (more positive) SOAs affecting later stages of target retrieval. Our results indicate that an early stage of written target name retrieval is constrained by phonological variables (i.e., facilitation at this stage is mainly determined by phonological target-distractor relatedness). This stage is followed by a subsequent processing stage in which phonology is no longer the only determinant of priming. Overall, our data do not allow one to distinguish between a scenario in which phonological access is followed by graphemic access and a scenario in which phonological access is followed by phonological and graphemic access. However, the results suggest that in the early stages of processing, phonology is clearly relevant. If it is assumed that the results reflect a sequence of phonological, followed by orthographic, processing, then it would be tempting to interpret them as evidence for phonological mediation; that is, a picture first activates its phonological representation, that is then converted to a graphemic code. However, given the substantial evidence that suggests the existence of a direct link between conceptual and graphemic codes (e.g., Rapp et al., 1997; see our introduction), we do not think that this account is tenable.

More likely, graphemic production is supported principally by both a direct link from conceptual knowledge and an indirect link via phonology, and studies such as the present one aim at gauging the relative influence of the two pathways. For instance, the model suggested by Bonin et al. (2001) assumes a semantic system that is symmetrically linked to both a phonological and an orthographic output lexicon. Both lexicons also directly map onto each other, implying that selection of a graphemic entry (as in handwriting) is influenced by both direct activation from the semantic system and indirect activation from the phonological lexicon. In addition, the model assumes a sublexical phonology-to-orthography conversion route, paralleling the sublexical grapheme-to-phoneme route in dual-route models of reading aloud (cf. Coltheart, Rastle, Perry, Langdon, \& Ziegler, 2001).

Within such a framework, our finding of an "early" processing stage in which priming is dominated by phonological relatedness may suggest that activation via the phonological pathway is transmitted relatively rapidly to the graphemic lexicon and that priming residing in this pathway is constrained by phonological overlap between distractor and target. Only slightly later (after the shift from $\mathrm{SOA}=0 \mathrm{msec}$ to $\mathrm{SOA}=+100 \mathrm{msec}$ ) does activation arrive via the direct pathway from semantics, and hence at this later stage, graphemic overlap exerts an ef- 
fect on latencies. This scenario is admittedly sketchy and needs to be strengthened with more explicit assumptions concerning the underlying processing mechanisms. It is, however, principally compatible with the previous findings from neuropsychological case studies (see the introduction) which have shown on the one hand, for example, that patients' spelling errors tend to be influenced by sound-tospelling inconsistency (and hence support a role of phonology), but, on the other hand, that some patients are able to provide written names of pictures that they are unable to name orally (and hence suggest an autonomous link from conceptual to orthographic representations). Given that patient performance could reflect compensatory processes as a result of the behavioral impairment, it could be argued that experimental data from unimpaired production are particularly important for settling the issue of phonological mediation versus orthographic autonomy.

We interpret the results of our second experiment as implying that participants, when engaging in simultaneous articulatory suppression, generated their written responses predominantly on the basis of activation transmitted via the direct link from semantics to orthography. Perhaps articulatory suppression "saturates" the phonological pathway or slows down processing in such a way that its influence on orthographic retrieval is no longer detectable. Again, the exact processing assumptions need to be specified more clearly. Overall, we believe that the data from the first experiment provide a better approximation of the "default" processing mode in which handwritten production is typically accomplished, and here the results clearly support the claim that writing is constrained by phonological codes. Hence, with regard to the small number of previous studies on unimpaired written production, we interpret our results as generally more in line with those that have suggested a role of phonology in such tasks (such as Bonin et al., 2001; see the introduction).

\section{AUTHOR NOTE}

This research was supported by International Incoming Fellowship IIF-2007/R1 from the Royal Society to the first author, and by Grant RES-062-23-0729 from the Economic and Social Research Council (ESRC) to the second author. Correspondence concerning this article should be addressed to M. F. Damian, University of Bristol, Department of Experimental Psychology, 12a Priory Road, Bristol BS8 1TU, England (e-mail: m.damian@bristol.ac.uk).

\section{REFERENCES}

Aitchison, J., \& TodD, P. (1982). Slips of the mind and slips of the pen. In R. N. St. Clair \& W. von Raffler-Engel (Eds.), Language and cognitive styles: Patterns of neurolinguistic and psycholinguistic development (pp. 180-194). Lisse: Swets \& Zeitlinger.

BaAYen, R. H., Davidson, D. J., \& Bates, D. M. (2008). Mixed-effects modeling with crossed random effects for subjects and items. Journal of Memory \& Language, 59, 390-412.

BaAyen, R. H., Piepenbrock, R., \& Gulikers, L. (1995). The CELEX lexical database (Release 2) [CD-ROM]. Philadelphia: Linguistic Data Consortium, University of Pennsylvania.

Baddeley, A. D., \& Hitch, G. J. (1974). Working memory. In G. H. Bower (Ed.), The psychology of learning and motivation (Vol. 8, pp. 47-89). New York: Academic Press.

Baddeley, A. D., Lewis, V., \& Vallar, G. (1984). Exploring the articulatory loop. Quarterly Journal of Experimental Psychology, 36A, 233-252.
Basso, A., Taborelli, A., \& Vignolo, L. A. (1978). Dissociated disorders of speaking and writing in aphasia. Journal of Neurology, Neurosurgery, \& Psychiatry, 41, 556-563.

BATES, D. (2005). Fitting linear mixed models in R. R News, 5, 27-30.

Bonin, P., \& FAYOL, M. (2000). Writing words from pictures: What representations are activated, and when? Memory \& Cognition, 28, 677-689.

Bonin, P., Fayol, M., \& Peereman, R. (1998). Masked form priming in writing words from pictures: Evidence for direct retrieval of orthographic codes. Acta Psychologica, 99, 311-328.

Bonin, P., Peereman, R., \& Fayol, M. (2001). Do phonological codes constrain the selection of orthographic codes in written picture naming? Journal of Memory \& Language, 45, 688-720.

Caramazza, A., \& Miceli, G. (1990). The structure of graphemic representations. Cognition, 37, 243-297.

Coltheart, M., Rastle, K., Perry, C., Langdon, R., \& Ziegler, J. (2001). DRC: A dual route cascaded model of visual word recognition and reading aloud. Psychological Review, 108, 204-256.

Costa, A., \& Sebastian-Gallés, N. (1998). Abstract phonological structure in language production: Evidence from Spanish. Journal of Experimental Psychology: Learning, Memory, \& Cognition, 24, 886-903.

Damian, M. F., \& Dumay, N. (2007). Time pressure and phonological advance planning in spoken production. Journal of Memory \& Language, 57, 195-209.

Damian, M. F., \& Martin, R. C. (1999). Semantic and phonological codes interact in single word production. Journal of Experimental Psychology: Learning, Memory, \& Cognition, 25, 345-361.

Damian, M. F., \& Stadthagen-Gonzalez, H. (2009). Advance planning of form properties in the written production of single and multiple words. Language \& Cognitive Processes, 24, 555-579.

DAVIS, C. J. (2005). N-Watch: A program for deriving neighborhood size and other psycholinguistic statistics. Behavior Research Methods, 37, 65-70.

Dell, G. S., Schwartz, M. F., Martin, N., Saffran, E. M., \& GaGNON, D. A. (1997). Lexical access in aphasic and nonaphasic speakers. Psychological Review, 104, 801-838.

Forster, K. I., \& Forster, J. C. (2003). DMDX: A Windows display program with millisecond accuracy. Behavior Research Methods, Instruments, \& Computers, 35, 116-124.

Geschwind, N. (1969). Problems in the anatomical understanding of the aphasias. In A. L. Benton (Ed.), Contributions to clinical neuropsychology (pp. 107-128). Chicago: Aldine.

Glaser, W. R., \& Düngelhoff, F.-J. (1984). The time course of picture-word interference. Journal of Experimental Psychology: Human Perception \& Performance, 10, 640-654.

HEAD, H. (1926). Aphasia and kindred disorders of speech. Cambridge: Cambridge University Press.

Hécaen, H., \& Angelergues, R. (1965). Pathologie du langage: l'aphasie. Paris: Larousse.

Hotopf, W. H. N. (1980). Slips of the pen. In U. Frith (Ed.), Cognitive processes in spelling (pp. 287-307). New York: Academic Press.

Houghton, G., \& ZorZI, M. (2003). Normal and impaired spelling in a connectionist dual-route architecture. Cognitive Neuropsychology, 20, 115-162.

Kandel, S., Álvarez, C. J., \& VAllée, N. (2006). Syllables as processing units in handwriting production. Journal of Experimental Psychology: Human Perception \& Performance, 32, 18-31.

KuČERA, H., \& Francis, W. N. (1967). Computational analysis of present-day American English. Providence, RI: Brown University Press.

Lesch, M. F., \& Pollatsek, A. (1993). Automatic access of semantic information by phonological codes in visual word recognition. Journal of Experimental Psychology: Learning, Memory, \& Cognition, 19, 285-294.

Levelt, W. J. M., Roelofs, A., \& Meyer, A. S. (1999). A theory of lexical access in speech production. Behavioral \& Brain Sciences, 22, 1-75.

LuPKER, S. J., \& KATZ, A. N. (1981). Input, decision, and response factors in picture-word interference. Journal of Experimental Psychology: Human Learning \& Memory, 7, 269-282.

LuRIA, A. R. (1966). Higher cortical functions in man (B. Haigh, Trans.). London: Tavistock. 
LuRIA, A. R. (1970). Traumatic aphasia: Its syndromes, psychology and treatment (D. Bowden, Trans.). The Hague: Mouton.

Miceli, G., Benvegnù, B., Capasso, R., \& Caramazza, A. (1997). The independence of phonological and orthographic lexical forms: Evidence from aphasia. Cognitive Neuropsychology, 14, 35-69.

Miozzo, M., \& Caramazza, A. (2003). When more is less: A counterintuitive effect of distractor frequency in the picture-word interference paradigm. Journal of Experimental Psychology: General, 132, 228-252.

RapP, B., Benzing, L., \& Caramazza, A. (1997). The autonomy of lexical orthography. Cognitive Neuropsychology, 14, 71-104.

RapP, B., \& CARAmazza, A. (1997). From graphemes to abstract letter shapes: Levels of representation in written spelling. Journal of Experimental Psychology: Human Perception \& Performance, 23, 1130-1152.

Schriefers, H., Meyer, A. S., \& Levelt, W. J. M. (1990). Exploring the time course of lexical access in language production: Picture-word interference studies. Journal of Memory \& Language, 29, 86-102.

Smyth, M. M., \& Silvers, G. (1987). Functions of vision in the control of handwriting. Acta Psychologica, 65, 47-64.

Starreveld, P. A. (2000). On the interpretation of onsets of auditory context effects in word production. Journal of Memory \& Language, 42, 497-525.

Starreveld, P. A., \& La HeiJ, W. (1995). Semantic interference, orthographic facilitation, and their interaction in naming tasks. Journal of Experimental Psychology: Learning, Memory, \& Cognition, 21, 686-698.

VAN GALEN, G. P. (1991). Handwriting: Issues for a psychomotor theory. Human Movement Science, 10, 165-191.

Wheeldon, L. R., \& Levelt, W. J. M. (1995). Monitoring the time course of phonological encoding. Journal of Memory \& Language, 34, 311-334.

\section{NOTES}

1. Throughout this article, production is used as a general term for cognitive processes arising from both response preparation and execution. Although this use of the term is common in research on spoken utterances, one could argue that aspects pertaining to response selection should be more adequately characterized as preparation, whereas the term production should be used exclusively with regard to response execution.

2. Because it has been suggested (Costa \& Sebastian-Gallés, 1998) that in PWI experiments with spoken responses and distractors, match/ mismatch of target and distractor concerning their abstract CV structure could affect latencies, we also analyzed the CV structure of our stimuli. For both the $\mathrm{O}$ and the OP conditions, the related and the unrelated conditions were statistically matched in proportion of picture-word combinations that shared $\mathrm{CV}$ structure.

3. One distractor item, dove, has an ambiguous pronunciation in that it could be pronounced either as the bird or as the past tense of dive. We analyzed the data from Experiment 1 while excluding the item, and found that the three-way interaction of relatedness, type of relatedness, and SOA just failed to reach conventional significance $[F(2,7779)=$ $\left.2.55, M S_{\mathrm{e}}=49,446, p=.078\right]$. More importantly, under SOA $=0 \mathrm{msec}$, we still found a significant interaction of relatedness and type of relatedness $\left[F(1,2576)=5.11, M S_{\mathrm{e}}=89,453, p=.024\right](\mathrm{O}$ facilitation $=$ $8 \mathrm{msec}$; OP facilitation $=32 \mathrm{msec}$ ); under the other two SOAs, no such interaction was found $\left(F_{\mathrm{S}}<1\right)$. The central findings were therefore not affected. We thank an anonymous reviewer for suggesting this analysis.

APPENDIX

Stimuli Used in Experiments 1 and 2

\begin{tabular}{|c|c|c|c|c|}
\hline Target & $\mathrm{O}$ & Unrelated & OP & Unrelated \\
\hline ball & shall & poor & wall & cork \\
\hline bear & year & youth & swear & loll \\
\hline boot & foot & ward & shoot & dread \\
\hline bread & read & wool & spread & crush \\
\hline brush & push & dove & crush & trap \\
\hline cap & swap & word & trap & south \\
\hline card & ward & year & yard & shove \\
\hline dart & wart & swap & part & cool \\
\hline doll & roll & swamp & loll & spread \\
\hline door & poor & wart & floor & sand \\
\hline fork & work & bead & cork & wall \\
\hline glove & dove & read & shove & yard \\
\hline hand & wand & work & sand & fruit \\
\hline harp & warp & foot & carp & swear \\
\hline head & bead & warp & dread & shoot \\
\hline lamp & swamp & broad & stamp & floor \\
\hline mouth & youth & swan & south & wear \\
\hline pan & swan & roll & $\tan$ & ford \\
\hline pear & fear & shall & wear & toad \\
\hline road & broad & push & toad & stamp \\
\hline sword & word & quit & ford & $\tan$ \\
\hline suit & quit & wand & fruit & carp \\
\hline stool & wool & fear & cool & part \\
\hline
\end{tabular}

Note-O orthographically related; OP, orthographically and phonologically related.

(Manuscript received March 20, 2009; revision accepted for publication November 18, 2009.) 